\title{
Perspectivas de controle da doença de Chagas no Brasil
}

\author{
* Faculdade de Medicina da \\ UFMG e SUCAM, Ministério da \\ Saude
}

\author{
* João Carlos Pinto Dias
}

\section{INTRODUÇÃO}

A doença de Chagas humana origina-se basicamente do contato homem-triatomíneo ao nivel domiciliar e, mais recentemente, em parcela menor mas não pouco significativa, da transmissão direta do Trypanosoma cruzi homem a homem, via transfusional. Os fatores destas interações apresentam condicionantes múltiplos, dentre os quais se destacam aqueles de natureza sócio-econômica e cultural 2 2, 43,44. Trata-se de uma enfermidade metaxênica, primitivamente uma enzootia silvestre ampla e difusamente dispersa em toda a América Latina. Na doença humana, os elementos bioecológicos são decisivamente influenciados pelo contexto social, essencialmente problemas enraizados no confronto das classes, no modelo político, nas relações de produção9, 22,43 . No que tange à implantação e expansão da endemia chagásica, tais determinantes são fundamentais num modelo teórico-explicativo que pretenda, em suma, identificar perspectivas de controle $8,12,43$. A paisagem geral das áreas gásicas, hoje, demarca-se precisamente pelos padrões sociais das populações: um espectro de pobreza, de más condições de vida e educação, uma frágil organização política, a doença coexistindo com a fome, a tuberculose, o analfabetismo e as enfermidades de veiculação hídrica, frutos de causas comuns 2 .

Ao lado disto, a questão concreta de milhões de chagásicos, em toda a área endêmica, uma parcela significativa já minada pela cardiopatia crônica, inexorável redutora da expectativa de vida. Em tal contexto emerge o controle como ponto crucial, que permeia a própria caracterização do social dos países onde a doença incida, resultante direta, também, dos modelos político-sociais vigentes, numa dependência extremamente desvantajosa desses povos com relação ao primeiro mundo 16 .

Recebido para publicação em $20 / 11 / 85$

Uma análise de controle da doença de Chagas envolve múltiplos aspectos e abordagens. A solução completa e defi- 
nitiva do problema depende de profundos câmbios na estru. tura social, política e econômica das regiões endêmicas. Não obstante, já se dispõe há algum tempo de tecnologia suficiente para o controle do vetor intradomiciliar e da transmissão transfusional, medidas capazes de reduzir drasticamente a incidência do mal, mesmo em se tratando de ações até certo ponto verticais e isoladas 19,24,42. A dimensão políticoadministrativa volta a apresentar-se implicada neste tema, especialmente no que toca às razões pelas quais as medidas já disponiveis não se implementaram com o rigor necessário, ou têm tardado tanto em grande extensão da área endèmi$\mathrm{Ca}_{38}$. Um Grupo de Trabalho do TDR 39 buscou avaliar a eficácia teórica das medidas de controle em 1980, para uma projeção matemática de uma comunidade rural latino-americana durante 20 anos. A Tabela 1 resume as principais informações obtidas na simulação quanto à prevalência, incidência e risco de transmissão do $T$. Cruzi ao homem, em diferentes categorias sociais. Observa-se ai que o inseticida e/ou inseticida associado à melhoria habitacional constituem medidas isoladas bastante eficazes em qualquer dos padrões sociais, quando em comparação ao grupo sem "nenhuma intervenção". Por outro lado, também é nítida a redução dos indices no grupo "nenhuma intervenção" somente com a elevação dos padrōes sociais das comunidades, o que reforça as observações existentes e as perspectivas delineadas neste sentido9, 39 .

\section{TABELA 1}

Valores do risco de transmissão,

da prevalência (\%) e da incidência (\%) para 20 anos de simulação em três diferentes padröes sociais de comunidades rurais latino-americanas, avaliadas sob seis tipos de intervenção antichagás ica. Adaptação de Rabinovich et al., TRD (1980)51..

Tipos de comunidades (padrĩo sócio-econômico)

Indicadores

1. Salário mínimo ou abaixo 2. Pequenos assalariados 3. Pequenos proprietários

\begin{tabular}{lccccccccc}
\hline Tipos de intervenção & $\begin{array}{c}\text { Risco } \\
\text { transm. }\end{array}$ & Preval. & Incid. & $\begin{array}{l}\text { Risco } \\
\text { transm }\end{array}$ & Preval. & Incid. & $\begin{array}{l}\text { Risco } \\
\text { transm. }\end{array}$ & Preval. & Incid. \\
\hline Nenhuma intervenção & 0,2123 & 80,7 & 2,70 & 0,0347 & 38,2 & 0,99 & 0,0013 & 17,8 & 0,10 \\
Inseticida & 0,0006 & 15,3 & 0,05 & 0,0001 & 14,7 & 0,01 & 0,0000 & 14,6 & 0,00 \\
Melhoria da habitação & 0,0237 & 45,5 & 1,14 & 0,0022 & 19,9 & 0,16 & 0,0013 & 17,8 & 0,10 \\
Tratamento em massa & 0,2011 & 79,7 & 2,68 & 0,0211 & 21,2 & 0,26 & 0,0000 & 14,6 & 0,00 \\
Vacinação ** & 0,2044 & 34,9 & 1,79 & 0,0302 & 18,7 & 0,30 & 0,0015 & 15,0 & 0,01 \\
Inseticida + habitação & 0,0003 & 15,1 & 0,03 & 0,0000 & 14,7 & 0,00 & 0,0000 & 14,6 & 0,00
\end{tabular}

${ }^{*}$ Hipoteticamente tratamento específico de todos os chagásicos, no ano 0 com as drogas hoje disponi. veis.

* Considerada hipoteticamente a existência de uma vacina segura e eficaz, para aplicação em toda a área endêmica, no ano 0.

Cadernos de Saúde Pública, R.J., 2 (1): 84-103, jan/mar,1986. 
${ }^{*}$ DIAS, J.C.P. Epidemiology of Chagas'disease in Brazil. In: $B R E N E R, R$. \& STOKA, $A$. (coord.) Chagas' disease vector. CRS Press, Boca Raton, Fl. USA - in press. 1985.

${ }^{*}$ DIAS, J.C.P. Doença de Chagas e a questão da tecnologia. Bol. of. SANIT' Panam., 1985. (em publ.)
Evidentemente os caminhos não se excluem. Câmbios sociais não são antagônicos com ações específicas. $O$ panorama epidemiológico da tripanosomíase é drástico na América Latina, verificando-se por exemplo, no Brasil, que, a preços correntes, o custo de 25.000 "marca-passos" estimados para chagásicos com necessidade específica, mais as cirurgias esperáveis de 15.000 megaesôfagos e 10.000 megacólons, poderia implicar em aproximadamente US\$ 248,000,000, suficientes à construção de 165.000 casas rurais higiênicas ou à desinsetização completa da área endêmica de Bolívia, Argentina e Brasil*. A experiência acumulada já demonstrou não apenas que o problema é concreto e grave em vastas extensões do Continente, mas também que os recursos destinados à saúde nestas áreas são poucos, mal distribuídos e mal aplicados. Tal cenário é ainda agravado pelo baixo crédito político dos Ministérios da Saúde nos países endêmicos, observando-se grandes descontinuidades político-administrativas que retardam e enfraquecem os programas46.Por detrás da questão da tecnologia, uma verdadeira guerra de interesses pode ainda criar sérios obstáculos à aplicação adequada e racional dos inseticidas no combate ao vetor ${ }^{*}$, fato que se agrava em freqüentes episódios de descontinuidade técnica e no desvio ou malversação de recursos específicos 12,38 .

$L \backslash^{+} \backslash \alpha \rrbracket \ell \backslash^{+} p \ell \backslash$ têm de ser investigadas como premissasbase da discussão sobre o controle da doença e suas estratégias, necessariamente a levar-se em âmbito interdisciplinar e com ampla participação comunitária. Releva ainda notar que, como problemática eminentemente latino-americana, há que se buscar prioritariamente uma tecnologia própria (local) de investigação e controle, que fuja aos modelos importados, muitas vezes descomprometidos e geradores de alienação e dependência ${ }^{12}$.

\section{O CONTROLE DA DOENÇA DE CHAGAS NO BRASIL: PANORAMA ATUAL}

O Controle de Vetor

Publicações recentes procuraram analisar as condições e circunstâncias da implantação de um programa de controle da doença de Chagas no País, contemplando-se a história do desenvolvimento dos recursos e técnicas ao lado da história das tomadas de decisão em aplicá-los na prática, ou seja, da priorização política do programa1 2,39,44,46. Pontificam no Brasil as opções pelo controle do vetor, basicamente através do uso de inseticidas de ação residual, com bons resultados ao nível dos dados entomológicos e de incidência. ${ }^{17,42,47}$. A figura 1 reproduz os dados dos inquéritos sorológicos para doença de Chagas em escolares do Estado de São Paulo, em anos sucessivos após a priorização 
da campanha antivetorial4 7. A queda progressiva da prevalência indica claramente a de incidência, restando assinalar que embora tenha havido concomitantemente, em todo o Estado, melhoria significativa do padrão habitacional, tem sido possivel avaliar em áreas restritas a grande importancia específica da desinsetização 1 7,33,42.

FIGURA 1.

Inquérito sorológico em escolares de 1 \% grau no Estado de São Paulo, de 1975 a 1983

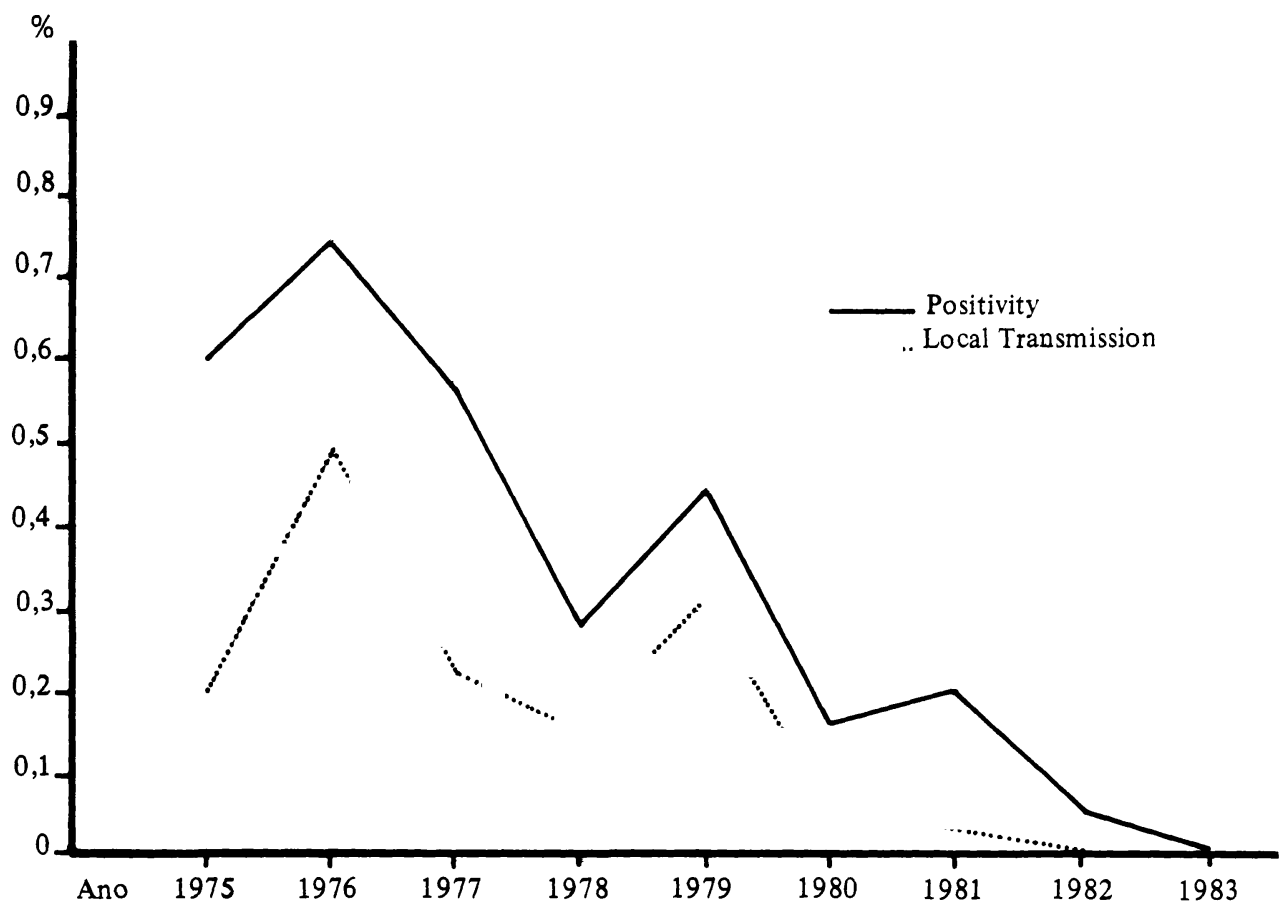

De modo geral, pode-se analisar a campanha antitriatomínica no Brasil, a partir dos dados pioneiros de Emmanuel Dias, em Bambuí, entre 1945 e 1960, com o estabelecimento das bases do modelo atual da SUCAM e do emprego de BHC em larga escala 18,19 . Estudos posteriores como os de Pedreira de Freitas 29 e Rocha da Silva 42 culminaram com a priorização da Campanha em São Paulo nos fins da década de 60, observando-se o mesmo para o Brasil, a partir de 198212,46 . As questões mais pertinentes ao controle do vetor, através de inseticidas, vêm sendo colocadas por diversos autores no Brasil, podendo resumir-se 1 2, 34,42.

1. Nem todas as espécies de triatomíneos apresentam resposta idêntica aos inseticidas usuais e nos esquemas correntes, seja em razão de diferentes sensibilidades aos produtos, seja por causa de diferenças no comportamento do ve- 
OPINIÃO

tor (espécies ubiquistas $\mathrm{X}$ espécies restritas ao ecótopo artificial). Este ponto pode ser contemplado nos gráficos abaixo (Figs. 2 e 3 ) que mostram os indicadores entomológicos disponiveis para $T$. sordida e $P$. megistus sob pressão de inseticida por vários anos, em regiões próximas.

\section{FIGURA 2.}

INDICADORES DO CONTROLE DE TRIATOMINEOS PELA SUCAM EM CICLOS

SUCESSIVOS DE TRABALHO

DIVISÃO: DOENÇA DE CHAGAS

ESTUDO EPIDEMIOLÓGICO

MUNICIPIO: IGAPORÃ

Estado: Bahia

Espécie predominante:

T. sordida

Indice de dispersão

Indice de infestação (UD)

Indice de infestação (ID)

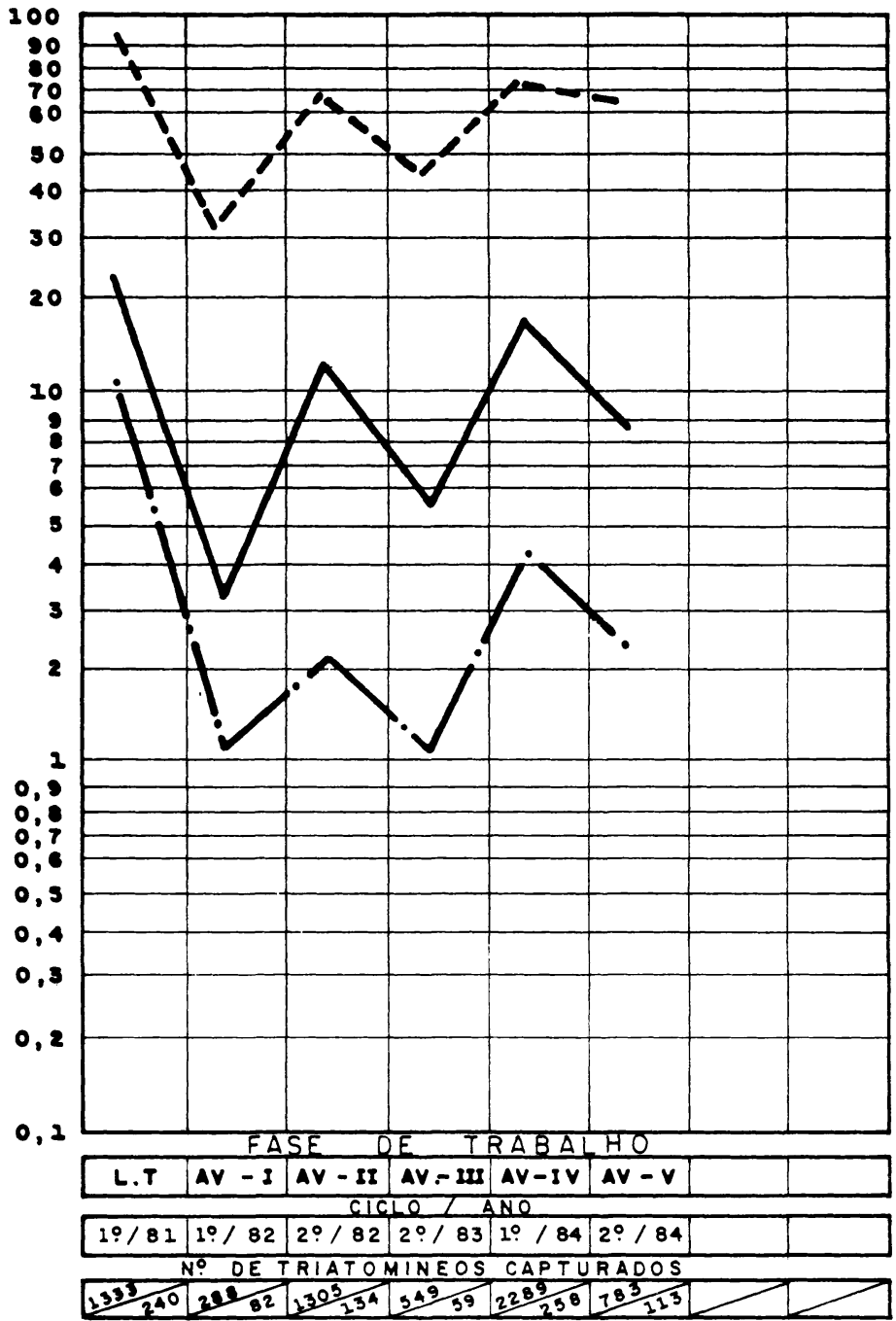

Cadernos de Saúde Pública, R.J., 2 (1): 84-103,jan/mar,1986. 


\section{INDICADORES ENTOMOLOGICOS DO CONTROLE DE TRIATOMÍNEOS PELA SUCAM EM CICLOS SUCESSIVOS DE TRABALHO \\ MS-SUCAM}

\section{Divisão: Doença de Chagas \\ ESTUDO EPIDEMIOLÓGICO \\ Município: Pedro Leopoldo}

\section{Estado: Minas Gerais}

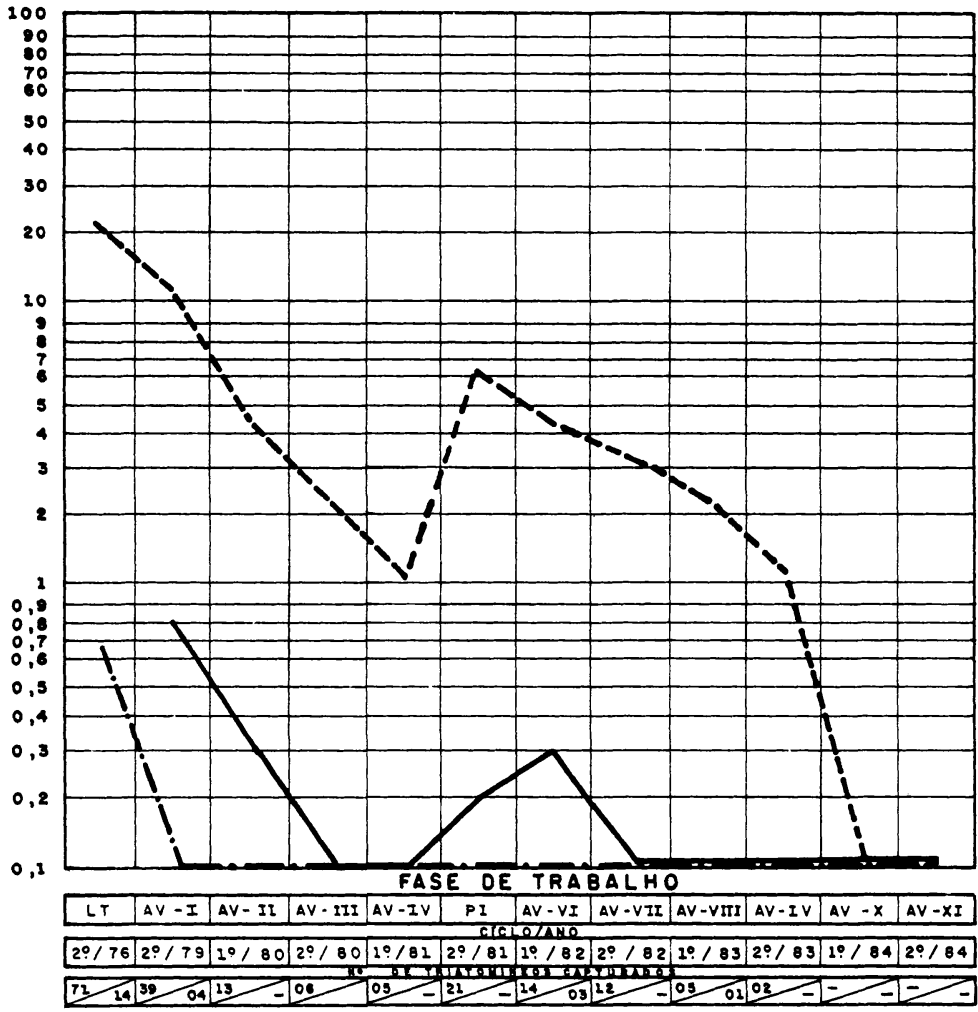

Espécie predominante:

P. megistus

Indice de dispersão

Indice de Infestação (UD)

Índice de Infestação (ID)

Deve-se anotar ainda, neste ponto, que não se constatou até hoje, no Brasil, o fenômeno de resistência aos inseticidas como observado na Venezuela para $R$. prolixus frente a clorados. A campanha brasileira tem usado $\mathrm{BHC}$, piretróides e fosforados (Malathion $\mathrm{R}$ ), até aqui sem problemas deste tipo36,42.

2. A resposta aos inseticidas é diferente para a mesma espécie de triatomíneo dentro das casas e no peridomicílio. Neste último, a ação é bem menos eficaz, por razões as mais 
diversas como desativação dos produtos pela luz, poeira, lavagem por chuva, dispersão por vento, etc. Experimentos recentes com diferentes piretróides no norte de Minas têm revelado níveis de controle de até $98 \%$ no intradomicilio durante 360 dias para $T$. infestans e $T$. sordida, contra $70 \%$ ou menos no âmbito peridomiciliar 21 . Neste sentido, devese ainda considerar que as espécies nativas e de maior valên. cia ecológica naturalmente apresentam-se muito mais problemáticas ao controle que aquelas mais restritas ao intradomicilio, fato que já Emmanuel Dias apontava em 1956 com referência a $P$. megistus $e T$. infestans 17,19 . Observações recentes de Silveira \& Borges 45 acentuam ainda que, em diferentes regiões, a mesma espécie pode mostrar-se mais ou menos adaptada ao intradomicilio, confirmando estudos clássicos, principalmente para P. megistus ${ }^{2,2} 7$.

3. O envolvimento da ação antrópica sobre o ambiente é da maior irnportância na perspectiva de controle. Dispensa maiores comentários a expansão de $T$. infestans no Brasil, basicamente dependente do fenômeno migratório 2,31,44. Os principais triatomíneos domiciliados ou em vias de domiciliação no Brasil, hoje, são $T$. sordida, $P$. megistus $e T$. brasiliensis, cujos habitats naturais são freqüentemente invadidos e modificados pelo homem, facultando a domiciliação no esquema epidemiológico clássico 2, $27 . \mathrm{Na}$ discussão de controle, dois fatos ligados a tal situação devem ser ponderados:

3.1. Em áreas de alta densidade ambiental destas espécies com ação antrópica de baixa ou moderada intensidade (sul do Piauí, sertão da Bahia, certas áreas do Triângulo Mineiro), a resposta entomológica ao inseticida por ser lenta e pouco eficaz, demandando trabalho a prazo muito longo (ver figura 2).

3.2. Em áreas sob alta ação antrópica como as de canaviais de São Paulo e dos eucaliptais em Minas os "reservatórios" silvestres de triatomíneos acabam por esgotar-se, permitindo respostas muito boas à profilaxia. Agreguem-se aqui, sem dúvida, fatores outros como a melhoria habitacional e a diminuição da densidade populacional humana como elementos auxiliares na redução da domiciliação triatomíni$\mathrm{Ca}^{8}, 16,22,39$.

3.3. Em áreas umbrosas, com desmatamentos e migração intensivas, há sempre a perspectiva de domiciliação de espécies nativas e/ou introdução passiva de espécies alienígenas. Amazônia e resíduos da Mata Atlântica estão nessa situação, a merecer cuidado específico e planejamento ocupacional adequado 16,27 .

4. Espécies ditas "secundárias" podem teoricamente domiciliar-se em circunstâncias específicas ou após o controle de $T$. infestans: Rhodnius neglectus, em Goiás, $R$. nasutus, 
no Nordeste, e T. rubrovaria, no Rio Grande do Sul, são situações-exemplo hoje observadas $2,6,46$. Os dados disponiveis, felizmente, indicam que o processo é lento, e que o risco de formação de grandes colônias domiciliares destas espécies é muito baixo, perfeitamente controlável através de um bom sistema de vigilância. Em Bambuí, MG, eliminado o $T$. infestans, que ali prevalecia em alt íssima densidade entre 1940 e 1958 , restou o $P$. megistus que vem sendo controlado satisfatoriamente com vigilância comunitária, enquanto que as demais espécies da área $(R$. neglectus, $T$. pseudomaculata e mesmo $T$. sordida) nunca passaram de achados raros e esporádicos nas capturas domiciliares, assim também como o $P$. diasi, ainda mais restrito ao ambiente silvestre da região ${ }^{7}$.

5. O carreamento passivo de triatomíneos para as grandes cidades é bastante freqüente em toda a área endêmica, especialmente naquelas regiões onde o modelo urbano-industrial fomenta maior migração rural urbana3 1,41. Não obstante, no Brasil, tem-se observado uma grande dificuldade de se implantarem triatomínicas de maior importância nos centros urbanos, apenas detectando-se focos esparsos e isolados de $T$. infestans (Rio, Belo Horizonte), $P$. megistus (Salvador, São Paulo) ou T. sordida (cidades de São Paulo, Triângulo Mineiro). A par destes focos facilmente erradicáveis, colônias pequenas e esparsas de $T$. rubrofasciata se desenvem em várias capitais da orla marítima, sem maior importância epidemiológica 2 .

6. A questão metodológica é fundamental na campanha antitriatomínica. No esquema brasileiro, após a fase de ataque, são previstas avaliações semestrais sucessivas da área, borrifando-se seletivamente as unidades domiciliares infestadas. Nesta etapa, é de grande importância a sensibilidade dos métodos de captura, que muitas vezes deixa a desejar. Mormente em focos com poucos triatomíneos, em tempo de frio, o risco de não se detectar uma casa "positiva" é bastante considerável. A consolidação das etapas mais avançadas de controle é, pois, complexa e muitas vezes lenta, especialmente quando em áreas de espécies ubiquistas. As equipes de captura necessitam grande mobilidade, ótimo treinamento e constante supervisão, não se podendo admitir, nesta fase, descontinuidades operacionais ${ }^{5}$.

Em suma, pode-se considerar que o panorama atual é satisfatório no que toca ao trabalho executado pela SUCAM (e pela SUCEN, em São Paulo). A metodologia e a opção do controle vetorial emergiram de circunstâncias próprias que permeiam uma antropozonase eminentemente rural do Terceiro Mundo, num contexto de difícil priorização das causas sociais. Há que se entender, assim, a própria postura da SUCAM, vertical, priorizando metas e coletividades. Os de- 
mais elos da cadeia epidemiológica como a habitação, a transmissão transfusional e o indivíduo infectado não têm sido objeto do programa nacional de Chagas no Brasil, por uma questão de escolha e de limitação operacional. Estes tópicos serão sumariados a seguir, porque fazem parte de uma visão mais ampla e que o momento histórico está a exigir sejam assumidos. Mais à frente, por fim, uma visão do panorama futuro do programa e da doença de Chagas no Brasil, com as perspectivas e as expectativas pertinentes. Como conclusão destas reflexões, é nossa opinião que o controle dos vetores da esquizotripanose tem sido alcançado no Brasil em vastas extensões onde praticamente se erradicou o $T$. infestans e em outras em que as densidades domiciliárias de triatomíneos infectados baixaram tan to que a transmissão já não mais ocorre ${ }^{12,47}$. Há ainda regiões-problema onde a ação profilática ainda não se efetivou com a agressividade requerida, em especial no sertão da Bahia e do Piauí. São chamadas "áreas de expansão", que entraram na programação tardiamente, só depois que os recursos do "Finsocial" realmente consolidarem o "poder de fogo" da SUCAM ${ }^{6}$. Uma idéia da importância destes recursos pode ser dada pelos números abaixo.

a) Até 1982 a SUCAM dispunha de recursos para borrifar ao redor de 500.000 unidades domiciliares (UD), chegando, no entanto, a 1.232 .331 em 1984, após recepção dos recursos adicionais;

b) só para o atendimento emergencial da região baiana de Lapa e Barra, com 50 municípios e 202 mil UD, estima-se que o custo do trabalho orce pelos 4.300 .000 dólares, no primeiro ano (37 bilhões de cruzeiros - nov./85).

Assim, conhecendo-se a experiência anterior que demonstrou sobejamente a inutilidade e os riscos de interromper programas, é fundamental hoje garantir-se no plano político o apoio técnico-financeiro que a SUCAM vem recebendo desde 1982, cuja descontinuidade poderá redundar em irreparável perda material, ao lado de um enorme descrédito político e institucional ${ }^{12}$.

\section{A Melhoria Habitacional}

Muito se fala de programas habitacionais para o controle dos tratomíneos, cabendo a Souza Araújo, em 1918, formalizar pela primeira vez um projeto de lei neste sentido, para o Estado do Paraná ${ }^{8}$. A habitação é ponto-chave na cadeia epidemiológica da tripanosomíase humana, mal estudado e muito sujeito a discursos e improvisações que longe ficam da realidade e das necessidades da população exposta ao "barbeiro". Pode estimar-se a necessidade de substituição de 600.000 "cafuas" nas áreas endêmicas brasileiras, destas, cabendo umas 150.000 em Minas Gerais, num custo aproxi- 
mado de US $\$ 1,000$ a 1,500 por unidade (cálculo OMS). Quem pode ou deve assumir isto? A SUCAM? As Secretarias de Saúde? A população chagásica, subempregada e esfomeada? o INCRA? o BNH?

A habitação diz muito mais de perto ao povo que o inseticida. A casa rural é o reflexo do homem rural, expressando na área endêmica a pobreza, a provisoriedade, a subagregação social do chagásico. Mexer na casa é mexer diretamente com as pessoas e com as relações entre as pessoas. Significa intervenção profunda, um revolver de toda a estrutura social, trazendo-se especificamente à tona os problemas da economia grupal, da posse da terra, das relações de posse, de poder e de trabalho.

Freqüentemente se fala em legislações específicas, em programas governamentais amplos, ou em projetos educacionais sobre a habitação rural, como solução definitiva do problema de Chegas. Experimentos e observações isolados têm realmente demonstrado que a boa habitação, limpa, clara, sem frestas nas paredes e outros esconderijos, rodeada por um peridomicílio organizado e higiênico, praticamente inviabiliza a colonização dos triatomíneos. São clássicos os dados de Fonseca e cols. ${ }^{2} 8$ que demonstraram, em São Paulo, que as casas de alvenaria e reboco albergavam significativamente menos triatomíneos e menos triatomíneos infectados que casas não rebocadas. Estas diferenças ficavam mais evidentes, ainda, em relação a casas de madeira e, ainda mais, se a comparação se fazia com casas de barro e pau-apique.

A prática de um programa habitacional é complexa e cheia de problemas. No Brasil, muitas vezes se tem verificado que a população não melhora suas casas por vários fatores, entre os quais a falta de posse do terreno, o desencanto e desestímulo face a gravíssimos problemas existenciais (subemprego, transitoriedade, falta de recursos). Experiências antigas já demonstram que a falta de entendimento com a população e o desconhecimento de seu universo vivencial podem dificultar a aceitação de programas e a participação comunitária. Relatam-se casos de rejeição a novas habitações porque se quiseram impingir regras, padronizar comportamentos, estruturar artificialmente a população ${ }^{23}$. É imprescindivel admitir-se que nem sempre as "verdades" e os padrões da gente urbana são necessariamente o que há de melhor para a população rural. Apesar do analfabetismo, do isolamento e da aparente ignorância em que vive o povo da roça, ele possui um agudo senso de observação sobre o que acontece a sua volta. São pessoas que enfrentam e resistem a imensas dificuldades. Elas pensam, conversam, dão opiniões, têm sonhos e desejos, e não simplesmente devem executar o que os outros decidiram 4,23 . 
Pouco, de concreto, se tem feito em termos da habitação rural em programas de Chagas, fora trabalhos experimentais. Em Minas, há experimentos isolados nas regiões de Montes Claros e do Vale do Jequitinhonha (Prodevale), a par de estudos sobre técnicas e materiais de construção desenvolvidos no Centro Tecnológico de Belo Horizonte (CETEC). Um programa habitacional rural, no Brasil, não pode ser assumido pelo Ministério da Saúde, mas deveria sêlo por outras instituições. A realidade dos modelos urbanoindustriais e a crecente desvalorização do homem e dos produtos rurais fazem sentir as poucas "shances" de um programa de habitação que seja amplo e coerente. Infelizmente não se. pode ser otimista enquanto a filosofia de órgãos como os Ministérios do Interior, da Agricultura e da Fazenda, tão alheia ou distante da realidade social de chagásicos e lavradores. Em recente simpósio sobre doença de Chagas, diretores do BNH expressaram que a moradia é problemática e de má qualidade no panorama rural brasileiro, e que o órgão precisaria assumir de vez uma opção concreta pelo rurícula, o que efetivamente ainda não fizera: "seja pela dificuldade primordial de ser obrigado a trabalhar com garantia real, em regime de hipoteca, ou por falta de recursos, não se instrumentalizou o Plano da Casa Rural - PLACAR, criado pelo Decreto no 85.876, de 03.04.81 (...) Será que construir a casa resolve o problema? Não seria necessário continuar fazendo dedetização?"3 5 .

Por outro lado, ao'nível da população, o problema de habitação é concreto, e sua discussão pode propiciar perspectivas de organização social, de ajuda mútua, cooperativismo, etc, aprofundando a reflexão dos problemas de base da comunidade, inclusive os políticos e sócio-culturais. Ȧ sua vez, o próprio uso da casa é elemento primordial na questão da tripanosomose, uma vez que hoie, no Brasil. o grande desafio é o do peridomicilio. É sumamente freqüente a construção de anexos domiciliares extremamente propícios ao "barbeiro", em conjuntos populacionais rurais ou urbanos de construções de alvenaria. Até que ponto será suficiente construir e olhar somente uma casa de tijolos, quando a maioria dos focos residuais ou de reinvasão triatomínica contra-se no peridomicilio?

Há todo um caminho a percorrer nesta grave e imediata questão habitacional. Ela necessita ser encarada com a devida profundidade e com recursos suficientes, evitando-se demagogia e palavreados estéreis. Ressalte-se, finalmente, que os programas habitacionais e a desinsetização não se excluem, mas devem compreender-se numa ação coerente, complementada por medidas educativas e de ampla promoção social ${ }^{12,23}$. 
O Controle da Doença Transfusional

É um problema diretamente afeto ao sistema operacional de saúde do País. Podemos analisá-lo sob dois enfoques principais, conforme o nivel da prática hemoterápica: os maiores centros e os serviços que estocam sangue e deriva. dos, de um lado, e a prática transfusional direta (pessoa-apessoa) das pequenas cidades, de outra. No primeiro caso, são pertinentes as ações de seleção de doadores por sorologia e a prática de adição de Violeta de Genciana $(1: 4000)$ a sangues estocados em Bancos, por 24 horas. Órgãos tipo "Hemocentros" podem facultar tanto a sorologia, como a distribuição de sangue e hemoderivados de boa qualidade, bem como a quimioesterilização. Esta última se faz em ampla escala no Estado de Goiás, há muitos anos, com excelente resultado e ótima orientação pelos médicos e pacientes*. A Secretaria de Saúde de Minas Gerais está montando na Fundação Ezequiel Dias, em Belo Horizonte, um laboratório-modelo para oferecer diagnóstico sorológico ao sistema de saúde, assim como para servir de centro de referência para laboratórios já em funcionamento na Capital e outras regiões do Estado. Para as cidades menores, onde a hemoterapia é eventual e ocorre em circunstâncias mais sin. gelas, a alternativa mais pertinente é o cadastramento e a seleção dos doadores. Isto se pode conseguir mediante sorologia bem conduzida, feita obrigatória e gratuitamente a nível dos Centros de Saúde, para processamento em laboratórios estratégicos da Secretaria. Em áreas de alta endemicidade e riscos de transmissão, a repetição periódica (anual) da sorologia é indicada. Já funciona na região de Uberaba, MG, um modelo experimental deste sistema, que hoje atende a doze municípios com boa aceitação da classe médica e população, sendo a sorologia executada pelo Centro Regio. nal de Saúde, em convênio com a Faculdade de Medicina do Triângulo Mineiro, a FIOCRUZ e o Programa de Salud Hu. mana, da Argentina 25 .

Vê-se, no entanto, que, de modo geral, o problema transfusional é grave no País. Estima-se que na área endêmica a prevalência de doadores infectados nos bancos de sangue oscile entre $0,5 \%$ e $5 \%$, o que pode estar resultando, hoje, em até 20.000 casos novos de transmissão da esquizotripanose por ano ${ }^{18}$. Na verdade, o problema tem sido encarado timidamente, sabendo-se inclusive que, em alguns pontos do País, campeia ainda impunemente um verdadeiro mercado de sangue e hemoderivados, sem controle nem punições. Como indicador de novos tempos, começa a circular no Senado Federal um projeto de Lei que tenta regulamentar a questão, inclusive remetendo à Justiça Comum os indivíduos ou instituições que pratiquem a hemoterapia fora das normas técnicas e sem cadastramento clínico-sorológico
${ }^{*}$ Rassi, A. Doença de Chagas transfusional. Colóquio intermacional sobre enfermedad de Chagas. Santa Cruz, Bolivia (no prelo) 
prévio dos doadores. ${ }^{*}$ Pode ser apenas mais uma lei sem efetivo cumprimento ou mecanismo de cobrança, mas é um bom passo inicial.

Finalmente, uma polêmica entre partidários da quimioprofilaxia $\mathrm{X}$ partidários do controle sorológico de doadores não faz sentido na hora presente. São medidas úteis e complementares, não se excluem absolutamente. A quimioprofilaxia constitui excelente maneira de prevenção, devendo ser implementada onde possível, principalmente em bancos de sangue de área endêmica. A triagem de doadores é perfeitamente equacionável em sistemas regionalizados de saúde (vide acima), podendo ser assumida pelo Estado. Cálculos realísticos demonstram que, mesmo com uma sensibilidade baixa (90\%), uma única reação sorológica reduz o risco teórico máximo de $0,5 \%$ para $0,05 \%$, que cai para $0,01 \%$ com o emprego de duas técnicas sorológicas simultâneas ${ }^{2} 0$. O que se nota, felizmente, é que, embora tardiamente, o assunto vem ganhando espaço na discussão e na concretização de medidas pertinentes. Sua priorização, como no caso do controle do vetor, vai se esboçando neste alvorecer de busca de resgate da dívida social do País, principalmente no bojo das perspectivas das ações integradas de saúde.

\section{O Controle do Infectado}

Como um todo, este tópico tem sido tratado de maneira empírica e isolada, ressaltando-se os vários trabalhos sobre terapêutica especifica 7,10 e sobre o diagnóstico e manejo das principais formas clínicas $114,26,30$. Na realidade, o sistema operacional de saúde não tem olhado de frente os 5 milhões de chagásicos do País, nem priorizado sua atenção num esquema organizado e fluido. Grandes avanços, não obstante, têm sido alcançado no que tange ao controle sintomático das arritmias 40 , da insuficiência cardíaca da fase crônica $^{32}$ e das formas digestivas ${ }^{4}$. Em paralelo, com o aprimoramento da Previdência Social e a urbanização da endemia, critérios médico-previdenciários vêm sendo desenvolvidos, e o grau de cobertura ao chagásico vem aumentando no País $1,11,13,26,49$, embora ainda longe do ideal, especialmente ao nivel da população campesina ${ }^{2} 2$. Admite-se que o controle médico-previdenciário precoce dos chagásicos crônicos pode ser perfeitamente realizado nos ambulatórios médicos do sistema operacional de saúde (SOSP) por clínicos gerais capazes de diagnosticar a infecção e as formas clínicas usuais, apenas instrumentados pelo recurso sorológico e - no máximo - pelo eletrocardiograma convencional ${ }^{14,20}$. A detecção de casos agudos é simples e facilmente realizável pelo médico do interior, viabilizando-se com tal diagnóstico não só um elemento epidemiológico importante para as ações de controle como, principalmente, 
o tratamento específico e a cura do caso ${ }^{1+, 15,18,26}$. Neste sentido, é fundamental que se torne a doença de Chagas aguda de notificação compulsória em todo o Brasil, como já determinado em São Paulo e em vias de determinação em Minas Gerais. A detecção precoce do chagásico crônico pelo SOSP será fundamental para:

a) controle da transmissão transfusional;

b) ajuizamento de sua condição laboratorial;

c) controle precoce de insuficiência cardíaca e das arritmias;

d) encaminhamento aos níveis de complexidade maior

do SOSP para tratamentos mais sofisticados e aos benefícios pertinentes da Previdência Social.

São temas presentes e atuais, a serem concretamente assumidos no momento em que se fala em "priorização social" e em "ações integradas de saúde". Deve-se insistir que a reversão do descaso pela doença de Chagas é também uma questão histórica de caráter ideológico, num sistema político-social que privilegia sociedades urbano-industriais em detrimento de populaçoes de "segunda classe" e problemas de "segunda classe". Está, portanto, a merecer tratamento político e tecnológico adequado, inclusive uma revisão de conteúdo e metodologia nos currículos universitários $14,20,49$.

No panorama atual da esquizotripanose no Brasil, foram estes os principais pontos a discutir no tema de controle. Questões outras podem ser levantadas, como as demais formas de transmissão, sem dúvida muito mais raras e de menor interesse em Saúde Pública. Ressalve-se que a transmissão congênita deve ser melhor analisada, principalmente no que se refere à prematuridade e natimortalidade ${ }^{3,18}$. A negativação da sorologia entre crianças e escolares nas áreas endêmicas de São Paulo e Minas Gerais, após as medidas convencionais de controle, no entanto, parecem demonstrar que a transmissão congênita deve ser muito discreta, sem maior expressão epidemiológica ${ }^{17,18,47}$. O controle sobre tal tipo de transmissão constitui-se hoje no tratamento específico da doença aguda dos recém-nascidos - filhos de mães chagásicas - que apresentarem parasitas no sangue, a que demanda uma prática médica eficaz e de ampla cobertu$\mathrm{ra}^{14}$. Transmissão acidental em laboratório e por transplante de órgãos são objeto de ações profiláticas bem definidas, em âmbito restrito. A transmissão pelo leite materno foi suspeitada em dois casos da literatura, um deles recentemente documentado, realmente não apresentando nenhuma importância no contexto da endemia.

\section{CONSIDERAÇÕES FINAIS: NECESSIDADES E PERSPECTIVAS}

Até aqui apresentou-se um quadro da doença de Chagas no País. Há problemas, ações a implementar, decisões a se- 
rem tomadas. Mesmo totalmente controlada a transmissão do $T$. cruzi ao homem, restariam milhøes de chagásicos a merecerem por longos anos atenção específica.

Pode-se notar cristalinamente uma reversão no quadro da transmissão vetorial, em boa parte como resposta à ação profilática. Foi válido pensar o modelo para $T$. infestans, responsável pela dramática redução de triatomismo domiciliar em centenas de municípios brasileiros. Observa-se que a decisão política viabilizou, finalmente, a ação efetiva con tra os vetores, certamente também como fruto de ampla discussão nos meios científicos. Hoje esta discussão se encaminha igualmente para a transmissão transfusional, fazendo emergir os "hemocentros", os laboratórios de triagem e os esquemas de quimioprofilaxia ${ }^{25}$.

$O$ quadro autoriza otimismo, na medida em que os indivíduos disponíveis refletem a interrupção da transmissão em extensas áreas, desde que se mantenham os recursos governamentais. Não obstante, exige realismo e trabalho, frente à situação de risco de decontinuidade técnica e administrativa nos programas e pesquisas em curso, riscos estes de natureza eminentemente política. $\mathrm{O}$ controle dos vetores, hoje em vias de consolidação de suas fases de "ataque" e "avaliação", caminha a largos passos para uma fase horizontal e de longo prazo, a "vigilância epidemiológica". A doença transfusional pode ser controlada, se efetivamente assumida pelo Estado, assim como se podem melhorar sobremaneira a quantidade e a qualidade de vida dos chagásicos, através de um esquema médico-previdenciário atuante. Há que se trabalhar integrada e dinamicamente nas diversas esferas operacionais. Há que se analisar continuamente o comportamento dos vetores e manter sob vigilância operati. va todas as formas de transmissão da doença. É doloroso e didático o exemplo da malária, eficientemente controlada em muitas áreas, enquanto resistente à ação profilática em muitas outras.

O momento político é favorável no Brasil, quando o discurso oficial emerge das discussões populares e se assenta na priorização do social e nas perspectivas de ações integradas. As macrodecisões abrem mesmo, a médio prazo, linhas concretas de mudança no contexto maior da endemia, especialmente nas questões da terra e das relações de produção.

Uma série de necessidades específicas quanto à pesquisa $\mathrm{e}$ o aprimoramento das questões do controle da esquistossomose no Continente foi exaustivamente debatida por técnicos e cientistas em recente reunião da PAHO/OMS, em Washington ${ }^{3}$. Com base no documento preliminar e na experiência vivida na comunidade científica e na Divisão de

Cadernos de Saúde Pública, R.J., 2 (1): 84-103,jan/mar,1986. 
doença de Chagas da SUCAM, poderíamos identificar como expectativas de controle da endemia no Brasil:

A curto prazo (até cinco anos):

1. erradicação do Triatoma infestans no Brasil e controle da infestação intradomiciliar dás demais espécies transmissoras na área endêmica;

2. aprimoramento da tecnologia de vigilância epidemiológica, com a entrada nesta fase de $50 \%$ a $70 \%$ dos Municípios da área endêmica;

3. aprimoramento das ações de controle no peridomicílio, especialmente num modelo participativo e de profundo conteúdo educacional;

4. demarragem definitiva do controle transfusional, que deverá ser assumido pelas Secretarias Estaduais de Saúde; aprimoramento do sistema de diagnóstico sorológico e da quimioprofilaxia;

5. a queda rápida e progressiva da incidência da infecção em toda a área endêmica, alcançando pelo menos níveis abaixo de $10 \%$ dos $50 \mathrm{mil} \mathrm{a} 100 \mathrm{mil}$ casos/ano hoje estimados

6. aprimoramento do sistema de atenção primária ao chagásico e do sistema previdenciário, especialmente ao nível das áreas rurais e pequenas cidades.

A médio prazo (cinco a quinze anos), incluindo expectativas específicas na área de investigação:

1. interrupção da transmissão vetorial, com a instalação de vigilância epidemiológica em $100 \%$ dos municípios da área endêmica. Equacionamento do problema do vetor no peridomicilio. Desenvolvimento de inseticidas e formulações alternativas. Desenvolvimento de vacina eficaz e segura (??);

2. cobertura do controle transfusional em pelo menos $80 \%$ do País;

3. consolidação do controle do infectado, especialmente através de:

- ampliação da cobertura médico-previdenciária ao limite máximo;

- aprimoramento de métodos e drogas na prevenção e cura das arritmias graves e insuficiência cardíaca;

- desenvolvimento de procedimentos e/ou drogas de ação química e imunológica capazes de estagnar o curso do processo mórbido;

- desenvolvimento de novos compostos tripanocidas capazes de curar a infecção crônica.

Como reflexão final, há que se pensar que muito já se conseguiu nos últimos 15 anos, especialmente à custa de grande esforço da comunidade científica. As expectativas acima são concretas e possíveis, um contínuo desafio. E gra-
* DIAS, J.C.P. Epidemiology of Chagas' disease in Brazil. In: BRENER, R. \& STOKA, A. (coord.) Chagas' disease vector. CRS Press, Boca Raton, Fl. USA - in press. 1985.

Cadernos de Saúde Pública, R.J., 2 (1): 84-103, jan/mar,1986. 
* DIAS, J.C.P. Doença de Chagas, e a questão da tecnologia. Bol. Of. Sanit. Panam., 1985. (em publ.) tificante ver-se que as conquistas se materializaram principalmente pelo trabalho realizado nos países endêmicos, com recursos, tecnologia e pessoal locais*.

No Brasil, deve-se ter consciência que Chagas é apenas um problema - uma doença de raizes sociais - em meio a inúmeros outros que, como dizia Carlos Chagas, impedem o desenvolvimento de nosso povo e nossa raça. Deve-se também ter em conta que outros povos e pessoas da América Latina esperam ansiosamente do Brasil o delineamento dos caminhos, a motivação e o apoio para seus próprios programas.

\section{REFERENCIAS BIBLIOGRĀFICAS}

1. ADJUTO, D.B. Assistência ao chagásico pelo INAMPS. In: CANÇADO, R.R. \& CHUSTER, M. Cardiopatia chagásica. Belo Horizonte, Fund. Carlos Chagas, 1985. p. 382-3.

2. BARRETO, M. P. Epidemiologia. In: BRENER, Z. \& ANDRA$\mathrm{DE}, \mathrm{Z}$. Trypanosoma cruzi e doença de Chagas. Rio de Janeiro, Guanabara Koogan, 1979. p. 89-151.

3. BITTENCOURT, A.L. Actual aspects and epidemiological significance of congenital transmission of Chagas' disease. Mem. Inst. Oswaldo Cruz, $79: 133-8,1984$. supl.

4. BORGES DIAS, R. Controle da doença de Chagas e desenvolvimento sócio-econômico em comunidade rural endêmica. R. Soc. bras. Med. trop., $17: 48,1984$. supl.

5. BRASIL. Superintendência de Campanhas de Saúde Pública. Manual de normas técnicas da campanha de controle da doença de Chagas. Brasília, Centro de Documentação do Ministério da Saúde, 1985.

6. BRASIL. Superintendência de Campanhas de Saúde Pública. Programa de controle da doença de Chagas; prioridades, informaçōes epidemiológicas. Brasilia, 1985.

7. BRENER, Z. Recent advances in the chemoterapy of Chagas' disease. Mem. Inst. Oswaldo Cruz, 79 : 149-55, 1984, supl.

8. BUCHER, E. H. \& ABALOS, J. W. Análisis de los factores que inciden en el control de la vinchuca en la región chaqueña, Argentina, Symposia, IV. Jorn. Argent. Parasitol.: 177-99, 1981.

9. CALDAS JR., A.L. Epidemiologia e controle da doença de Chagas; relação com a estrutura agrária na região de Sorocaba S.P. São Paulo, 1983. 183 p. Tese de Mestrado; Depto. de Med. Prev. - Fac. Med. - USP

10. CANÇADO, J. R. Tratamento específico In: CANÇADO, J. R. \& CHUSTER, M. Cardiopatia chagásica. Belo Horizonte, Fund. Carlos Chagas, 1985. p. 327-55.

11. COURA, J. R. Doença de Chagas como endemia urbana. In: CANÇADO, J. R. \& CHUSTER, M. Cardiopatia chagásica. Belo Horizonte, Fund. Carlos Chagas, 1985. p. 356-61. 
12. DIAS, J. C. P. Análise e perspectiva de controle da doença de Chagas no Brasil. R. bras. Malariol. D. trop., 35 : 109-19, 1983.

13. DIAS, J. C. P. Aspectos previdenciários da doença de Chagas no Brasil. Bol. C. Est. INAMPS, Minas Gerais, 12 : 13-34, 1981.

14. DIAS, J.C.P. Clínica e terapêtica da doença de Chagas, Belo Horizonte, Secretaria de Estado da Saúde, 1981.74 p.

15. DIAS, J. C. P. Diagnóstico laboratorial da fase aguda. In: CANÇADO, J.R. \& CHUSTER, M. Cardiopatia chagásica. Belo Horizonte, Fund. Carlos Chagas, 1985. p. 384-5.

16. DIAS, J. C. P. Doença de Chagas. In: GUIMARĀES, R. (org.) Saide e medicina no Brasil; contribuição para um debate. Rio de Janeiro, Graal, 1978. p. 53-76.

17. DIAS, J. C. P. Doença de Chagas em Bambui, Minas Gerais, Brasil; estudo clínico-epidemiológico a partir da fase aguda entre 1940 e 1982. Belo Horizonte, 1982. 376 p. (Tese Fac. Med. UFMG).

18. DIAS, J.C.P. Mecanismos de transmissao. In: BRENER, Z. \& ANDRADE, Z. Trypanosoma cruzi e doença de Chagas. Rio de Janeiro, Guanabara Koogan, 1979. p. 152-74.

19. DIAS, E. Profilaxia da Doença de Chagas. O Hospital, 51 285-98, 1957.

20. DIAS, J. C. P. Situação atual de controle da doença de Chagas no Brasil. In: REUNIÃO ANUAL SOBRE PESQUISA BÂSICA EM DOENÇA DE CHAGAS, 12\% ., Caxambu, nov. 1985.

21. DIAS, J.C.P.; BENEDITO, V. \& VASCONCELOS J.R.A. Ensaio de campo com Permethrin e Cypermethrin contra triatomíneos em áreas endêmicas. $R$. Soc. bras. Med. trop. $17: 52$, 1984. supl.

22. DIAS, J.C.P. \& BORGES DIAS, R. Aspectos sociais, econômicos e culturais da doença de Chagas, Ci. e Cult., 31 :105-18, 1979. supl.

23. DIAS, J.C.P. \& BORGES DIAS, R. Housing and the control of vectors of human Chagas' disease in the State of Minas Gerais, Brazil. Bull. PAHO, 16:117-29, 1982.

24. DIAS, J. C. P. \& BORGES DIAS, R. Participação da comunidade em programas de controle da doença de Chagas. In: SITU. AÇÃO e perspectivas de controle das doenças infecciosas e parasitárias. Brasília, UnB, 1981. p. 293-312.

25. DIAS, J. C. P. \& BRENER, S. Chagas' disease and blood transfusion. Mem. Inst. Oswaldo Cruz, $79: 139-47,1984$. supl.

26. DIAS, J.C.P.; CANÇADO, J.R. \& CHIARI, C.A. Doença de Chagas. In: NEVES, J Diagnóstico e tratamento das doenças infecciosas e parasitárias. Rio de Janeiro, Guanabara Koogan, 1978. p. $582-611$.

27. FORATTINI,O. P. Biogeografia; origem e distribuição da domiciliação de triatomíneos no Brasil. $R$. Saúde públ., $14: 265$ 99,1980 .

28. FONSECA, A. et alii. In: MARTINS, A.V. \& PESSOA, S.B. Parasitologia médica $11^{\mathrm{a}}$ ed. Rio de Janeiro, Guanabara Koogan, 1982.

29. FREITAS, J. L. P. Profilaxia da moléstia de Chagas. In: CANÇADO J. R. (org. ed.). Doença de Chagas. Belo Horizonte,

Cadernos de Saúde Pública, R.J., 2 (1): 84-103, jan/mar,1986. 
Imp. Oficial, 1968. p. 541-59.

30. GUIMARÃES, A. C. O tratamento da insuficiência cardíaca no chagásico. In: CONGRESSO INTERNACIONAL SOBRE DO. ENÇA DE CHAGAS. Rio de Janeiro, 1979. Anais. Rio de Janeiro, FIOCRUZ, 1979. 221 p.

31. LITVOC. J. Doença de Chagas e processo migratório no estado de São Paulo. São Paulo, 1977. 82 p. (Tese de Mestrado, Dept. Med. Prev. - Fac. Med. - USP).

32. LOPEZ, M. Tratamento da Insuficiência cardíaca miocardiopatia chagásica crônica. In: CANÇADO, J. R. \& CHUSTER, M. Cardiopatia chagásica. Belo Horizonte, Fund. Carlos Chagas, 1985. p. 302-13.

33. MACEDO, V. O. Influência da exposição à reinfecção na evolução da doença de Chagas; estudo longitudinal de cinco anos. Patol. trop., 5 : 33-116, 1976.

34. MARTINS, A. V. Epidemiologia. In: CANÇADO, J. R. Doença de Chagas. Belo Horizonte, Imp. Oficial, 1968. p. 225-60.

35. NEPOMUCENO, T.. B. Melhoria da habitação rural. In: CANÇADO, R.J. \& CHUSTER, M. Cardiopatia chagásica. Belo Horizonte, Fund. Carlos Chagas, 1985.

36. OLIVEIRA FILHO, A. M. New alternatives for Chagas' disease control. Mem. Inst. Oswaldo Cruz., 79 : 117-23, 1984. supl.

37. ORGANIZACION PANAMERICANA DE LA SALUD. Informe de un grupo de estudio para analizar estrategias de control de la enfermedad de Chagas. Versão preliminar. Washington, $1984.44 \mathrm{p}$.

38. PRATA. A.; SILVA, E. O. R. ; SILVA, G. R.; ALENCAR, J. E.; COURA, J.R. \& ? BRENER, Z Documento elaborado pelo grupo de pesquisadores convidados pelo Ministério da Saúde para discussão e análise do combate à doença de Chagas pela SUCAM. In: SITUAÇÃO e perspectivas de controle das doenças infecciosas e parasitárias. Brasília, UnB, 1981.

39. RABINOVICH. J. (coord.) Informe de un grupo de trabalho sobre modelo matemático na epidemiologia e controle da doença de Chagas. Caracas, TDR, WHO/UNDP/WB, 1981.

40. RASSI, A.; LORGA, A. \& RASSI, S. G. Diagnóstico e tratamento das arritmias na cardiopatia crônica. In: CANÇADO, J. R. \& CHUSTER, M. Cardiopatia chagásica. Belo Horizonte, Fund. Carlos Chagas, 1985. p. 274-87.

41. REZENDE, J. M. Manifestações digestivas da moléstia de Chagas. In: CANÇADO, J R. Doença de Chagas. Belo Horizonte, Imp. Oficial, 1968. p. 442-80.

42. ROCHA E SILVA, E. O. Profilaxia. In: BRENER, Z. \& ANDRADE, Z. Trypanosoma cruzi e doença de Chagas. Rio de Janeiro, Guanabara Koogan, 1979.

43. SILVA, G. R.; LITVOC, J.; GOLDBAUM, M. \& DIAS, J. C. P. Aspectos da epidemiologia da doença de Chagas. Ci. e Cult., $31: 81-103,1979$. supl.

44. SILVA, L. J. Evolução da doença de Chagas no estado de São Paulo. Ribeirão Preto, 1981. (Tese; Fac. Med. - Ribeirão Preto).

45. SILVEIRA, A. C. \& BORGES, R. Potencial de domiciliação das principais espécies de triatomíneos na transmissão da doença de Chagas no Brasil. In: REUNIÃO ANUAL SOBRE PESQUI- 
SA BÁSICA EM DOENÇA DE CHAGAS, 12. Caxambu, 1985.

46. SILVEIRA, A. C. \& SAKAMOTO, T. Importância médico-social da doença de Chagas no Brasil e de seu controle. $R$. bras. Malariol. D. trop., $35: 127-34,1983$.

47. SOUZA, A. G.; VALERIO-WANDERLEY, D.M.: BURRALI. G.M. \& ANDRADE, J.C.R. Consolidation of the control of Chagas' disease vectors in the state of São Paulo. Mem. Ins. Oswaldo Cruz, $79: 125-31,1984$. supl.

48. SOUZA ARAÚJO, H. C. A doença de Chagas no Paraná. Mem. Inst. Oswaldo Cruz, $52: 477,1954$.

49. ZICKER, F. A cardiopatia chagásica como causa de incapacida. de laborativa; aspectos previdenciários em área urbana. Goiânia, 1985. 219 p. (Tese de Mestrado; Inst. Patol. Trop. e Saúde Pública - UFGo). 